\title{
XIV. On a case of lightning; with an evaluation of the potential and quantity of the discharge in absolute measure
}

\section{R.S. Brough}

To cite this article: R.S. Brough (1877) XIV. On a case of lightning; with an evaluation of the potential and quantity of the discharge in absolute measure, Philosophical Magazine Series 5, 4:23, 105-110, DOI: $10.1080 / 14786447708639305$

To link to this article: http://dx.doi.org/10.1080/14786447708639305

Published online: 13 May 2009.

Submit your article to this journal $[\pi$ 
ments. This expectation has been so far fulfilled that I think a short account of the experiments may not be uninteresting to your readers.

The magnet consisted of a bar of soft iron 2 feet 2 inches long and $2 \frac{1}{4}$ inches in diameter, on which were two helices containing each about 1030 turns of wire. It was excited by ten quart Grove cells arranged in series. The submagnet consisted of a wedge of soft iron 5 inches long by 2 inches thick at the wide end, and having an edge $2 \frac{1}{4}$ inches long.

The magnet being placed horizontally, the submagnet was brought up against its polished end, but prevented from touching it by two pieces of copper "bell"-wire. The light of a paraffin-lamp was polarized by a large Nicol's prism and allowed to fall on the pole at about $45^{\circ}$. The reflected light was examined by the Jellett analyzer described by me in the Philosophical Transactions for 1877, part 1 . The effect was most marked and distinct.

The following readings of the plane of polarization were taken:-

\begin{tabular}{|c|c|}
\hline Current direct. & Current reversed. \\
\hline $\begin{array}{ll}271 & 55 \\
271 & 57\end{array}$ & $\begin{array}{ll}271 & 30 \\
271 & 27\end{array}$ \\
\hline $\begin{array}{ll}271 & 54 \\
271 & 52\end{array}$ & $\begin{array}{ll}271 & 28 \\
271 & 26\end{array}$ \\
\hline Mean doubl & $26^{\prime} 45^{\prime \prime}$ \\
\hline
\end{tabular}

I have not as yet been able to get any distinct effect without the submagnet. Until this can be done, "absolute" measures of the amount of rotation due to a given strength of pole will not be possible.

Pixholme, Dorking.

J. E. H. GORDoN.

XIV. On a Case of Lightning; with an Evaluation of the Potential and Quantity of the Discharge in Absolute Measure. By R. S. Brovgh*.

TTHE south-west monsoon of 1871 may be considered to have 1 been characterized in the neighbourhood of Calcutta no less by its copious and protracted rainfall than by the violence and frequency of its thunderstorms. During the progress of

* Communicated by the Author, having been read before the Asiatic Society of Bengal on the ith of February, 1877. 
one of these storms in the early part of the monsoon, one of the trees standing near the gate of the compound of the building then occupied by the Sadr Diwáni Adálat, and now used as the European Military Hospital, in Lower Circular Road, was struck by lightning. The branches of this tree overhung the wires of the telegraph-line, from which they were only about a foot distant. The discharge passed from the tree to the wires (of which there are four), broke fourteen double-cup porcelain insulators, and passed to earth through the iron standards on which the wires are supported.

The one ends of all the four wires were connected to earth through instruments in the Calcutta Telegraph office, at a distance of about $5 \frac{1}{2}$ miles from the locality of the accident. The other ends were connected as follows to earth through instruments-the first at the Telegraph workshops (a distance of less than $\frac{1}{4}$ mile), the second at the Lieutenant-Governor's residence (less than $\frac{1}{2}$ mile), the third at Atchipur (less than 14 miles), and the fourth at Diamond Harbour (less than 25 miles). At the moment of the discharge nothing extraordinary was noticed at any of these offices.

It is often far too generally stated in text-books that lightning invariably follows the best conductor to earth. This statement is misleading at the best, and is absolutely untrue if the word "conductor" be employed in the sense to which it is usually restricted in electrical science. In this instance, for example, we find that the lightning broke fourteen insulators, each having probably an electrical resistance of several thousand megohms, in preference to traversing a wire-resistance of not more than $500 \mathrm{ohms}$ to earth through the receivinginstrument in the telegraph-workshops. The writers appear to overlook the fact (experimentally illustrated long ago by Faraday) that there is exerted a mechanical stress proportional to the square of the potential tending to produce disruptive discharge, as well as an electromotive force proportional to the simple potential tending to produce a conductive discharge. Thus the discharge may occur either along a path of minimum mechanical resistance or along a path of minimum electrical resistance. Which form of discharge will occur in any particular instance depends, of course, on the special circumstances of the case ; but, generally speaking, as the potential increases, the tendency naturally is, cateris paribus, for the disruptive to predominate over the conductive. In the case of lightning the potential is so great, that, for any form of "lightning-protector" to be efficient, the conductive facilities offered must be correspondingly great; that is, the protector must offer no sensible resistance to earth, otherwise a disrup- 
tive discharge may take place from the protector itself, which under these circumstances becomes merely a source of danger*. This tendency to disruptive discharge is taken advantage of to protect telegraph-instruments from lightning. An earthwire is brought very near to the line-wire, from which it is insulated by only a very thin stratum of air ; when the potential of the line-wire rises abnormally, a disruptive discharge takes place at this point, and the receiving-instrument is thus saved.

I have twice lately seen it stated that Sir W. Thomson found that the resistance of air to disruptive discharge decreased as the thickness of the stratum increased; and a French writer has referred the possibility of the oceurrence of lightning discharges several kilometres in length to this canse. Sir W. Thomson's narlier experiments certainly showed this unexpected result, probably due to the minute distances at which he was operating; but a later series of experiments, made at larger distances, showed this result in a much less marked degree; and Sir W. Thomson himself says, "it seems most probable that at still greater distances the electromotive force will be found to be sensibly constant, as it was certainly expected to be at all distances" $\dagger$.

Another assertion of the text-books is that the metallic rods now employed as lightning-protectors on buildings do not "attract" lightning. This statement is literally true, according to the meaning of the word "attract," but is untrue in effect; for such a rod lightning-protector determines a line of maximum induction, and a discharge is more likely to occur at the place than if the protector were not there. Professor Clerk-Maxwell does not appear to hold this opinion; but it seems to me unquestionable that if a charged thunder-clond; driving before the wind, is carried over a building furnished

* It is very necessary, therefore, that all systems of lighining-protectors should be tested for resistance from time to time. Mr. Schwendler's method of quantitatively testing "earths" has already been described before the Society (Journ. As. Soc. of Bengal, part 2, vol. xl. 1871). In this method two temporary auxiliary earths are required. Calling the resistance of the lightning-discharger earth $x$, and that of the auxiliary earths respectively $y$ and $z$, the three resistances $x+y=a, x+z=b$, and $y+z=c$ are measured br any accurate method most convenient (e.g. Wheatstone's bridge, differential galvanometer, tangent- or sine-galvanometer, \&c., or even nn empirically calibrated galvanoscope), the mean of positive and negative readings being taken to eliminate any natural elertromotive force between the earths. From the results thus obtained the unknown resistance $x$ can be calculated by the formula

$$
x=\frac{a+b-c}{2} \text {. }
$$

+ Papers on Electrostatics and Magnetism, p. 259. 
with a lofty metallic rod, discharge is more likely to occur than if the rod were away. In proof of this I may refer to the case reported by Mr. Pidgeon in 'Nature,' and subsequently discussed before the Society of Telegraph Engineers (Proceedings, May 12, 1875), in which the flagstaff acted the part of an ordinary "lightning-protector."

Professor Clerk-Maxwell observed, in his paper recently read before the British Association at Glasgow, that such lightningprotectors are designed rather to relieve the charged cloud than to protect the threatened building. In fact lightningrods are legitimately employed for this very purpose in the vineyards, where the object in view is to relieve charged clonds and prevent disruptive discharges and the consequent showers of hail.

Under ordinary circumstances, however, the noise and light of the lightning-flash must be regarded as a very harmless, if disagreeable, way of getting rid of some of the potential energy of electrical separation.

The protection of cities on the same principle, even if necessary or desirable, would be too expensive and unsightly ever to be put in practice. But Faraday has proved that if our houses were made of metal, they would constantly remain at the potential of the earth, we should virtually be "underground," and live within them in perfect security. The iron churches occasionally employed in Europe fulfil this condition exactly. It is not, of course, usually practicable to live in metal houses; but we can live in almost equally effective metal cages formed by running conductors connected to earth along the summit, eaves, and corners of our houses*.

The usual rod protectors appear to be only suitable to such structures as themselves determine lines of maximum induction, e. g. church-spires, factory-chimneys, flagstaffs, \&c.

The case of lightning referred to at the beginning of this paper is of peculiar interest, because we know precisely the mechanical effect produced by the flash, and from this we can work back and estimate roughly the potential and quantity of the electrical discharge.

In the first place we can calculate the force required to burst the cylindrical portion of the porcelain insulator into which the iron stalk is cemented.

Let $r=$ radius of the inside of the cylinder,

$$
\mathbf{R}=\quad \text { outside },
$$

and $\mathrm{F}=$ the resistance to bursting;

* This portion of the paper was written before the Meeting of the British Association at Glasgow. 
then

$$
\mathrm{F}=f^{\frac{\mathrm{R}^{2}-r^{2}}{\mathrm{R}^{2}+r^{2}}}
$$

where $f=66 \times 10^{4}$ grammes on the square centimetre.

Now the line-wire was bound to the insulator by a thinner wire passing round it. The surface-density could not have been uniform round the binding wire, but must have been greatest on the side touching the insulator.

By the method of electrical images in two dimensions it may be shown that the surface-density $(\sigma)$ on the inner sido of the binding wire is approximately

$$
\sigma=\frac{\mathrm{Q}}{4 \pi^{2} \mathrm{R} \sqrt{\bar{d}-a(\sqrt{d+a}-\sqrt{d-a})}},
$$

where $\mathrm{Q}$ is the total charge on the binding wire, $d$ the distance of the binding wire from the stalk of the insulator, and $a$ the radius of the binding wire. But

whence

$$
\begin{aligned}
2 \pi \sigma^{2} & =\mathrm{F}, \\
\therefore \sigma & =\sqrt{\frac{\mathrm{F}}{2 \pi}} ;
\end{aligned}
$$

$$
\mathrm{Q}=\sqrt{\frac{\mathrm{F}}{2 \pi}} \cdot 4 \pi^{2} \mathrm{R} \sqrt{\overline{d-a}}(\sqrt{d+a}-\sqrt{d-a}),
$$

which is the expression for the quantity of the charge on one insulator. As there were fourteen insulators broken, this result must be multiplied by fourteen in order to obtain the total quantity of the discharge.

Again, the electrostatic capacity of the binding wire is

$$
\mathrm{S}=\frac{2 \pi \mathrm{R} c}{\log \epsilon \frac{d+\sqrt{d^{2}-c^{2}}}{d-\sqrt{ } d^{2}-a^{2}}}
$$

where $c=1 \cdot 9$ about.

But $\mathrm{VS}=\mathrm{Q}$;

$$
\begin{aligned}
\therefore \mathrm{V}=\frac{\mathrm{Q}}{\mathrm{S}}= & \sqrt{\frac{\mathrm{F}}{2 \pi}} \cdot \frac{2 \pi}{c} \sqrt{d-a}(\sqrt{d+a}-\sqrt{d-a}) \\
& \times \log \epsilon \frac{d+\sqrt{d^{2}-a^{2}}}{d-\sqrt{d^{2}-a^{2}}}
\end{aligned}
$$

which is the expression for the potential of the discharge.

Now, in the particular case under consideration, 
$r=1.500$ centim.,

$\mathrm{R}=3.000$ centims.,

$d=2 \cdot 250 \quad$,

and $\quad a=0.125$ centim.

Hence $\mathrm{F}=396 \times 10^{3}$ grammes per square centimetre,

$$
\left.\begin{array}{rr}
14 \mathrm{Q}= & 50586.5 \\
\mathrm{~V} & =722.7
\end{array}\right\} \text { absolute electrostatic C.G.S. units. }
$$
find

Changing the units to the ordinary ones in practical use, wo

$$
\begin{aligned}
14 \mathrm{Q} & =16.86 \text { microfarads, } \\
\mathrm{V} & =216810 \text { volts }
\end{aligned}
$$

Assuming the sparking-distance to increase as the square of the potential, it can be calculated from the experimental results obtained by Messrs. Warren De La Rue and Müller (Proc. Roy. Soc. Jan. 1876), manely that 1000 rod-chlorideof-silver cells give a spark 0.009166 inch, that a difference of potentials of 216,810 volts would produce a spark in air between two electrodes at a distance of about 36 feet apart. This is, of course, a relatively very short distance; but it must be remembered that we have only taken into consideration that portion of the energy of the discharge which was employed in breaking the fourteen insulators, and have neglected all that was spent in heat, light, \&c.

XV. On the Nature of what is commonly termed a "Vacunm." By $\mathbf{S}$. Tolver Preston.

1. T T may perhaps not be uninteresting to consider what light the researches of Professor Maxwell on molecular distances in connexion with the kinetic theory of gases, and those of Sir William Thomson and others, are capable of throwing upon the physical condition of what is ordinarily termed a "vacuum." This inquiry might have an additional interest at the present time, when experiments with extremely rarefied media in connexion with the radiometer and the discharge of electricity in evacuated tubes are going on, and certain inferences regarding the condition of "vacua" would Jead one to infer that a prevalent idea may exist regarding the state of a "vacuum" (so termed) which is not consistent with facts, as indeed I am not aware that any special investigations have been made on this subject. I make no pre-

* Communicated by the Author. 